\title{
Guardianes de la real justicia: alcaldes de indios, costumbre y justicia local en Huarochirí colonial ${ }^{*}$
}

\author{
JOSÉ CARLOS DE LA PUENTE LUNA \\ Texas State University \\ jd65@txstate.edu
}

RENZO HONORES

Instituto Internacional de Derecho y Sociedad

rhonoresg@gmail.com

\begin{abstract}
RESUMEN
Este trabajo examina la construcción local del Derecho en San Damián de Urotambo - una comunidad de Huarochiri- en el temprano siglo XVII. En los pueblos de naturales, los alcaldes, usualmente indios notables y principales, ejercieron activa jurisdicción en su calidad de jueces y, en la resolución de disputas, hicieron uso del Derecho castellano. Los alcaldes, representantes del poder regio, fueron centrales en la circulación de conocimientos jurídicos; ellos mismos estaban muy familiarizados con las prácticas judiciales y notariales castellanas y las pusieron en práctica. Los litigantes fueron igualmente agentes importantes en este proceso de creación jurídica. Invocaron no solamente el Derecho europeo, sino que sus peticiones se apoyaron en las tradiciones jurídicas de origen precolombino. Este trabajo muestra cómo ambas esferas legales — castellanas y andinas - se entremezclaban y eran negociadas por jueces y litigantes
\end{abstract}

* Nuestro reconocimiento a Alan Durston por compartir con nosotros dos documentos sobre don Cristóbal Choquecasa, una donación y un arrendamiento, ambos de 1637, los cuales se discuten en la segunda sección de este ensayo.

HISTORIOA XL.2 (2016): 11-47 / ISSN 0252-8894

https://doi.org/10.18800/historica.201602.001 
en un fenómeno de interlegalidad. Estos agentes locales jugaron un rol activo en la construcción del Derecho colonial y las dimensiones plurales del orden legal en San Damián de Urotambo.

Palabras clave: cultura legal, costumbre, alcaldes de indios, Cristóbal Choquecasa, Perú siglo XVII

\section{ABSTRACT}

This essay examines the local construction of law in San Damian de Urotambo — an indigenous community in Huarochiri - in the early seventeenth century. In Andean towns, the alcaldes (magistrates), commonly members of the local nobility, had jurisdiction over dispute resolution and made use of Castilian law. These alcaldes, representatives of royal power, were central actors in the circulation of legal knowledge. They were also experts in the usage of Castilian judicial and notarial practices. Likewise, litigants were key agents in the process of creating a new juridical order by invoking both European and Pre-Columbian juridical traditions. This essay illustrates how these two legal spheres - Castilian and Andean - mingled and were negotiated by judges and litigants through a process of interlegality. These legal agents played a crucial role in the making of colonial law within the plural dimensions of the juridical world of San Damian de Urotambo.

Keywords: legal culture, costumbre, alcaldes de indios, Cristóbal Choquecasa, seventeenth-century Peru 
F 16 de julio de 1637, don Martín Astoricra y don Cristóbal Eaucarcaxa retornaron a su pueblo de San Francisco de Sunicancha. Allí los esperaba una carta de don Lorenzo Paullorayco en la cual este curaca del ayllu Concha reducido en el vecino pueblo de San Damián de Urotambo los retaba con "palabras injuriosas" a encontrarse, ese mismo día, para establecer la propiedad de unas chacras de una vez por todas. Significativamente, don Lorenzo demandaba que lo hicieran «como naupa y antiguos que peliaban los yngas». En efecto, durante las dos jornadas anteriores, y bajo la autoridad de Paullorayco, los hombres y mujeres de Concha llegaron a los terrenos, cortaron los árboles que los delimitaban y arrancaron las papas que crecían en este paraje del Rímac alto, en la provincia centroandina de Huarochirí. La gente de Concha también desbarató la acequia que irrigaba los campos, removiéndola desde sus cimientos, y comenzó a traer agua por un nuevo canal señalado para este efecto. Asimismo, tomaron dos carneros de los pastos de los dos principales, dando de garrotazos a la mujer y a las hijas de uno de ellos cuando estas fueron a reclamarlos al pueblo antiguo de San Cristóbal de Concha, donde el ayllu del mismo nombre había residido hasta la creación de las primeras reducciones. Los indios las arrastraron por los suelos, les arrebataron sus llicllas, les quebraron sus topos y las regresaron con las manos atadas a San Damián. Fieles a su palabra, el día anunciado en la carta, don Lorenzo y los hombres y mujeres de Concha se presentaron otra vez en la chacra, armados con garrotes y cuchillos y dando voces «que benga aquí a que le a de costar la uida que os matare». Pero don Martín y don Cristóbal se negaron a defender con sus armas las tierras que ellos llamaban Huacaycocha porque, según explicaron después, «para Eso teneamos Justiçia y no açer como antigo, que peliaban los yngas». Ese mismo día, presentaron su querella por escrito ante el corregidor de naturales, poniéndose bajo el amparo de Su Majestad. ${ }^{1}$

1 «Martín Astorirayco y Cristóbal Paucarcaxa, indios del pueblo de San Francisco de Sunicancha, contra don Lorenzo Pablo Rayco del pueblo de San Cristóbal de Concha sobre las tierras y demás deducido", 1637. Biblioteca Nacional del Perú, B1483, ff. 14r-17v. Diversos aspectos de este expediente, los cuales retomamos en la penúltima sección de este ensayo, han sido analizados en Salomon 1998. 
Pero el corregidor devolvió la causa al alcalde y a un regidor de San Damián, encomendándoles que, con la asesoría del principal don Cristóbal Choquecasa y en presencia de los alcaldes de Sunicancha, levantaran las informaciones necesarias para pronunciar su fallo. Así lo hicieron, ejerciendo su jurisdicción como lo habían hecho en otros pleitos conexos a esta causa. Este ensayo discute el rol de los cabildos de indios de Huarochirí en la resolución de este tipo de disputas. Modelados a partir de los concejos o ayuntamientos ibéricos durante las décadas de 1560 y 1570 , estos y otros cabildos de naturales funcionaban ya a fines de la centuria como juzgados de primera instancia, es decir, espacios jurisdiccionales con un grado significativo de autonomía. ${ }^{2}$ Su existencia se sustentaba en la capacidad de sus miembros de representar el poder regio y encarnar algunas de sus virtudes más altas, como la justicia. Dicha representación devino en uno de los mecanismos consustanciales al establecimiento del orden monárquico en el Nuevo Mundo. ${ }^{3}$

La vitalidad de estas corporaciones municipales en tanto ámbitos judiciales vino a depender, por tanto, de la capacidad de sus oficiales electos para resolver disputas en nombre del rey, apelando a la noción pluralista y en apariencia externa o impuesta de «justicia real», pero imbricando, gestionando y, en el proceso, transformando múltiples universos normativos andinos e ibéricos. Proponemos que esta dinámica configuró un escenario de interlegalidad, el cual pone de relieve las formas de articulación y las contradicciones características de los circuitos de administración de justicia en los corregimientos de indios. ${ }^{4}$ Dichos espa-

2 Por «jurisdicción», los tratadistas de la época entendían una atribución judicial que confería la capacidad de administrar justicia en materia civil, criminal y canónica (Hevia Bolaños 1989, I: 19). En este artículo, el término «autonomía» alude concretamente al grado de independencia (y autogobierno) indígena respecto de poderes locales como la Iglesia y las autoridades civiles espańolas (Guevara Gil y Thome 2009: 35-40).

3 Black 2010: 227-228; Cañeque 2004: 19-36; Herzog 2004: 62; y Premo 2005: 2-11, 27-31.

4 Por «interlegalidad» entendemos el uso, la coexistencia y la transformación de diversos ordenamientos jurídicos en un espacio social específico, los mismos que configuran una situación de porosidad normativa (Guevara Gil 2011: 32-39; Guevara Gil y Thome 2009: 43-47; y Santos 1987: 297-298). El Derecho Castellano no era monolítico, ya que 
cios estuvieron marcados por la coexistencia de normatividades locales y globales referidas, en este caso concreto, a la posesión de la tierra y al control del agua. La noción de multinormatividad propone capturar el Derecho dentro de este universo o constelación normativa más amplios, un espacio de negociación articulado por «modalidades», "capas» o «esferas» normativas no estructuradas por la idea secular, letrada y codificada de la ley. ${ }^{5}$ La creación, recepción, aplicación e inscripción de la ley en este tipo de pleitos constituían formas de traducción e intercambio cultural modelados por las prácticas sociales vigentes, la transmisión de saberes étnicos y legales, y las condiciones específicas en las cuales los actores locales recreaban marcos normativos coloniales y globales.

Este tipo de justicia local o comunal se convirtió progresivamente en un elemento dinámico controlado por especialistas en aspectos procesales y doctrinales que construían, rediseñaban y aplicaban estratégicamente argumentos legales inspirados en diversos métodos para la resolución de conflictos. Dado que gestionar la justicia real era siempre cuestión de defender, negociar y hacer prevalecer intereses locales, la fundación y constante utilización de estos espacios jurisdiccionales facilitó la incorporación de estos municipios y de las comunidades indígenas en general a la estructura judicial más amplia del Imperio español. Desde sus pueblos, a estos gestores de la real justicia les cupo un papel fundamental en la construcción «desde abajo» de la monarquía hispánica en los Andes. ${ }^{6}$

Trabajos recientes han resaltado el significativo impacto de este tipo de espacios jurisdiccionales en la vida de quienes, como los indios de Sunicancha y San Damián, transitaban por ellos en diversos roles. Como diversos autores advierten, sin embargo, los contornos y particularmente

comprendía numerosas fuentes de creación legal (Kagan 1981: 21-51). Este pluralismo y la vigencia social y legal de la costumbre como fuente de Derecho eran propios de los imperios modernos (Belmessous 2012; y Ross y Stern 2013: 109-141).

5 Duve 2013: 21-23.

6 Blockmans y otros 2009; Brendecke 2012; y Cardim 2012. Sobre la relación entre Estado en los Andes y la «justicia», en tanto elemento legitimador de su existencia, véase Spalding 2015. Ella es autora, además, del estudio clásico sobre Huarochirí (Spalding 1984: 125-126, 216-217), de cuyas páginas proviene la información sobre estructuras sociales y tenencia de la tierra que sirve de trasfondo a este ensayo. 
los contenidos de esta jurisdicción han permanecido invisibles en el registro histórico andino. La reconstrucción de las elusivas funciones judiciales de los cabildos rurales durante el reinado de los Habsburgo se ha visto reducida a lo prescrito en las ordenanzas toledanas para los pueblos de indios y en otras disposiciones de menor alcance, limitando drásticamente el análisis histórico de cómo operaba la justicia en estos ámbitos de articulación entre comunidades conquistadas y monarquía. ${ }^{7}$

Aunque dichas normas constituyeron un marco de referencia común hasta fines del período colonial, las mismas no siempre se siguieron en la práctica. Los pueblos de indios fueron terreno fértil para la aparición de nuevos actores y prácticas consuetudinarias que dieron vida propia a las pautas establecidas en la legislación. Este estudio documenta la participación directa e inmediata de alcaldes, escribanos y otros oficiales de república — entendida esta como la expresión política del pueblo que vive en policía - en la administración local de justicia, incluso en materias contenciosas de las que, supuestamente, los oficiales de cabildo quedaban excluidos. El estudio de estos procedimientos de negociación y resolución de disputas permite mostrar cómo, a partir de un proceso de selección basado en saberes y entendimientos comunes y a veces implícitos, los actores legales en disputa activaban ciertas opciones normativas mientras que mantenían otras inactivas o subyacentes, dependiendo de los intereses y destinatarios en juego. Así, el pleito por las tierras de Huacaycocha y los litigios interrelacionados que sirvieron para anclarlo en la historia legal de Huarochirí permiten explorar por primera vez un espacio concreto de jurisdicción indígena andina local y escudriñar los contenidos específicos de la misma. Con excepción de algunos fragmentos de escritura pública notarial, este expediente es uno de los tres únicos casos que conocemos hasta ahora, para la región andina en su totalidad, en que estos oficiales aparecen dirimiendo procesos judiciales sumarios por escrito. ${ }^{8}$

7 Burns 2011; Graubart 2015: 197, 217 y 222; Graubart 2016; y Mumford 2012.

8 Graubart 2015: 200-201. Los otros dos casos son el publicado por Jeremy Mumford en este volumen y un expediente elaborado por el cacique don Marcos Taques y su improvisado notario Francisco Guapastal en Tulcán (Nueva Granada) en 1654 (Rappaport y Cummins 2012: 124-126). 
La versión de don Lorenzo Paullorayco, principal del ayllu Concha, sobre los sucesos de julio de 1637 difería de la de sus adversarios en algunos puntos importantes. De acuerdo con su querella, presentada ante el mismo corregidor de Huarochirí el 20 de julio, la parcialidad de Concha que él lideraba se había limitado a aderezar el camino real que pasaba por sus tierras, para lo cual había tenido que cortar algunos árboles. Además, los indios de Concha habían obtenido ya, entre otros mandamientos más antiguos, un decreto del virrey ordenando al corregidor que, mientras se proveía justicia en esta materia, el ayllu fuese amparado en la posesión de los terrenos que ellos llamaban Conpurcaya y Ayxaguayque, entre otros nombres, y que decían poseer desde tiempo inmemorial.

El 15 del mismo mes, siempre según el testimonio de don Lorenzo, tras ser notificados de este decreto por el escribano de cabildo de Sunicancha, el alcalde don Gonzalo Curimanya, así como don Martín Astoricra, don Cristóbal Paucarcaxa y otros indios principales de Sunicancha, se habían apercibido con garrotes y cuchillos. Dando «retos y bravatas» mientras recorrían el camino y cortaban algunos árboles pertenecientes a la parcialidad de Concha, los hombres de Sunicancha se habían desplazado una legua hasta el pueblo antiguo para asesinar a don Lorenzo. Al no encontrarlo allí, le habían enviado recados a San Damián, desafiándole a que «si yo era onbre de bien que saliesse a encontrar con ellos». Don Lorenzo también dijo haberse negado a caer en la provocación, afirmando en su querella ante el corregidor: "yo no quise yr por acudir al remedio de la real justiçia y para que semejantes delictos se castiguen y se estorben alborotos y disençiones». ${ }^{9}$ Así, ambos bandos apelaron a la confrontación violenta para resolver el conflicto y establecer la propiedad de los terrenos en disputa. Simultáneamente, afirmaron la necesidad de que se aplicase «el remedio» de la justicia del rey, declarando su confianza en ella y acusando a la otra parte de ignorarla para sus fines particulares. ${ }^{10}$

9 «Martín Astorirayco y Cristóbal Paucarcaxa», ff. 14r-v, 17r-v.

${ }^{10}$ Don Lorenzo Paullorayco demandó a los de Sunicancha por haber ignorado el decreto del Conde de Chinchón (r. 1629-1639) que se les había notificado formalmente, 
Esta preferencia por la justicia real no era un intento mecánico de atraer al corregidor, la instancia superior, a las causas respectivas. Más bien, se trataba de una medida para garantizar la autonomía de la esfera legal municipal y salvaguardar las competencias judiciales de sus autoridades, quienes pasarían a administrar justicia. ${ }^{11}$ En términos generales, esta invocación a la justicia regia era una muestra de cómo una compleja teoría política de origen alto-medieval había echado raíces ya en los antiguos dominios de Pariacaca, dios tutelar de la zona. Dicha teoría se reflejaba en el convencimiento de los actores de la legitimidad social de la «justicia regia», basada a su vez en la premisa de que el monarca era un juez justo y protector que representaba a Dios en la Tierra. ${ }^{12} \mathrm{La}$ justicia era, por tanto, parte del «buen gobierno», un sucedáneo natural del poder regio. ${ }^{13}$

Sin embargo, al menos en primera instancia, esta larga disputa estuvo directamente en manos de los alcaldes de Sunicancha y San Damián, así como de otros actores indígenas. Su autoridad, tal y como se encargaron de enfatizar, también encarnaba esa justicia regia: ellos eran alcaldes y jueces "por Su Magestad». Así, aunque la justicia era uno de los atributos inmanentes del rey, eran los cabildos de Huarochirí los llamados a

actuando en todo momento "con poco temor de Dios y de la real justicia» (Ib., ff. 14r-15r). En representación de don Lorenzo y de su gente, el protector general de los naturales en Lima también acusó a estos indios particulares de Sunicancha de irrumpir en los terrenos «de su autoridad y de hecho», es decir, «sin tener derecho alguno» (Ib., f. 17r). ${ }^{11} \mathrm{Al}$ respecto, véase el ensayo de Caroline Cunill sobre los mayas de Yucatán colonial incluido en este número especial.

${ }^{12}$ Sobre el poder de los reyes para hacer justicia en lo temporal y legislar (Las Siete Partidas 1985: Partida II, Título I, Leyes 1 y 2).

${ }^{13} \mathrm{El}$ «buen gobierno» se identificaba con la administración de justicia, la paz social y el manejo responsable de las finanzas públicas (Calabria y Marino 1990: 1). Su relación con la justicia se puede rastrear en los juicios de residencia. En 1578, uno de los primeros cargos contra el alcalde de la villa de Santa (en la actual región Áncash) fue el haber denegado la administración de justicia a los vecinos y moradores. «Juicio de residencia contra don Juan de Mata y otros», 1579. Archivo General de la Nación [en adelante AGN], Juicios de Residencia, I: 1, f. 42r. La literatura formularia también era enfática sobre la primacía que tenía la averiguación del estado de la administración de justicia local en los juicios de residencia (Pérez Landero 1696: 171-179). 
administrarla directamente en la instancia local. Bajo el manto benevolente de la justicia real se cobijaba, en realidad, un territorio autónomo de negociación de poder local y autogobierno en parte heredero de las antiguas estructuras sociales y los universos normativos de los ayllus huarochiranos del tiempo del Inca.

\section{«JUESES DESTA CAUSSA»}

En Huarochirí, así como muy probablemente en muchas otras partes de los Andes a inicios del siglo XVII, la administración local de justicia recaía, en buena medida, en estos actores ahora enfrentados. El expediente que discutimos revela la participación rutinaria y experta de alcaldes, regidores y otras autoridades municipales en este tipo de procesos y diligencias, incluso en contravención de lo estipulado por las ordenanzas toledanas de $1575 .{ }^{14} \mathrm{El}$ nombramiento de don Juan Puquia, "procurador deste dicho pueblo elejido en el cavildo y regimiento del» como «defensor» de un indio acusado de idolatría en Pasco en 1617 —una causa independiente de la de Huarochirí- confirma el reconocimiento muy probablemente generalizado que autoridades civiles y eclesiásticas en los Andes hacían en la práctica del grado de destreza procesal y jurídica de algunos de los miembros de estos concejos. ${ }^{15}$

14 «Y ordeno y mando, que no conozcan los dichos alcaldes de pleitos [...] de tierras que litigue un pueblo con otro, ni sobre indios a quien deban pertenecer, porque de todo esto ha de conocer el corregidor» (Sarabia Viejo 1986-1989, II: 222). La normativa sobre las atribuciones judiciales de los primeros alcaldes, regidores y alguaciles de los naturales en los pueblos de indios incluye las disposiciones de Andrés Hurtado de Mendoza (r. 1556-1560) para el valle de Lima y la ciudad de Cuzco, las cuales iniciaron el proceso de reconocimiento oficial de la jurisdicción y la costumbre indígenas (Hanke y Rodríguez 1978, I: 46-47; Levillier 1921-1926, I: 290). Sobre la orden de 1559 de Cañete a Polo de Ondegardo para que dispusiese la elección de alcaldes para las nuevas parroquias de naturales, véase Navarro Gala 2015: 32-36. Para la continuación de esta política en la costa norte y Jauja, véase Levillier 1921-1926, III: 116-130; y Rostworowski 1975.

${ }^{15}$ El visitador de la idolatría caracterizó al acusado como «yndio menor [que] tiene necesidad de defensor», y a su defensor como «yndio ladino y de raçon». "Causa de hechicero de oficio contra Tomás Parinanca, yndio», Pasco, 1617. Archivo Arzobispal de Lima, Visitas de Hechicerías e Idolatrías, I: 4, s/f. 
El proceder del corregidor que admitió ambas querellas en Huarochirí es otro ejemplo paradigmático de este fenómeno, así como una muestra de la plena vigencia de prácticas establecidas en la provincia durante los cincuenta años anteriores, cuando la fundación de los primeros cabildos. ${ }^{16}$ Probablemente, sea indicativo también de una praxis más general. El corregidor no solo acató el decreto del virrey Conde de Chinchón que portaba don Lorenzo Paullorayco, lo que tendría poco de sorprendente, sino que comisionó la causa al alcalde de San Damián y a uno de sus regidores. A ellos les ordenó que, tras elaborar la información de testigos de rigor, le remitiesen todos los autos para sentenciar. El escribano de cabildo de San Damián debía citar particularmente, es decir por escrito e individualmente, a todas las partes. Como garantía del debido proceso, don Cristóbal Choquecasa, a quien nos referiremos luego, debía sumarse a los dos alcaldes durante las diligencias. En los días siguientes, los alcaldes, un regidor y Choquecasa, a quienes tanto el escribano de San Damián como el de Sunicancha identificaron repetidamente como «jueses desta caussa", se trasladaron a esta última localidad. Allí, nombraron escribano, notificaron a las partes, emitieron citaciones y levantaron la información solicitada, interrogando a siete testigos, firmando por aquellos que no sabían hacerlo y rubricando todos los autos contenidos en los diez folios que finalmente enviaron al corregidor. ${ }^{17}$

Esta comisión de funciones a los principales y oficiales de república, antes que una medida excepcional, parecía ser ya la costumbre en Huarochirí. ${ }^{18}$ Aunque en este caso el corregidor se reservó la potestad

${ }^{16}$ Jiménez de la Espada 1881, I: 61. El rol de alcaldes y escribanos, quienes además actuaban como lenguas, está documentado para las últimas décadas del siglo XVI (Salomon 2003: 257-258). El panorama indígena letrado en Jauja en esta misma época se explora en Puente Luna 2016.

${ }^{17}$ "Martín Astorirayco y Cristóbal Paucarcaxa», ff. 16r-22r. Luego de casi un mes de silencio, el corregidor decretó que, debido a «algunas nulidades en el pleito» (que no especificó) y a que estaba de partida hacia Aymaraes, la causa fuese concluida por su lugarteniente. Este no pudo determinar el pleito, por lo que ordenó que ambas partes acudiesen a la Audiencia. Por sentencias de vista y de revista, esta adjudicó la posesión de las tierras a los indios del ayllu Concha en 1639, desatando una serie de nuevos pleitos en las dos décadas siguientes (Ib., ff. 19v, 29r, 30r, 86r).

${ }^{18}$ Ib., f. 148r. 
de sentenciar, los autos y recaudos reunidos con motivo de la causa de 1637 revelan que algunos de estos conflictos locales se resolvían, en forma oral o escrita, en el cabildo (o entre cabildos), sin llegar necesariamente a manos del corregidor o de la Audiencia. La decisión de don Martín Astoricra y don Cristóbal Paucarcaxa de elevar su querella por las tierras de Huacaycocha ante el corregidor en 1637 se produjo solo después de que estos presentasen una petición ante el alcalde ordinario de Sunicancha en la que reclamaban su actuación para alcanzar justicia. El alcalde, luego de visitar los terrenos y comprobar en persona que la parcialidad de Concha «tenia mucha gente» $\mathrm{y}$ «tanto poder», tuvo que resignarse a redirigir a los litigantes hacia el corregidor. Además, durante la querella de 1631 que sirvió de antecedente a la de 1637, Astoricra y Paucarcaxa habían presentado una petición ante el alcalde de San Damián en la que afirmaron que ya otro alcalde se había negado a hacer las averiguaciones, destinando los productos de sus tierras al beneficio de la iglesia del pueblo. ${ }^{19}$ En otras palabras, todos estos litigantes recurrieron al corregidor no porque no existieran otras instancias sino porque el pleito, debido a su naturaleza intrapueblerina, difícilmente podría resolverse en un solo cabildo.

Un ejemplo adicional de autonomía judicial nos sitúa en 1615. Don Lorenzo Anchiñaupa y don Gonzalo Puypoguaman, alcaldes ordinarios de San Damián "por el Rey nro. Señor", ejecutaron un auto del corregidor que ordenaba a los indios de Sunicancha que no invadiesen con sus ganados los terrenos de don Lorenzo. Los dos alcaldes emitieron un mandamiento, firmándolo ellos y el escribano de cabildo. En él, advertían que, de no acatar su mandato, "yo embiaré a su costa un alguazil para que lo traygan a este dho $\mathrm{pu}^{\mathrm{o}}$ y no obediente de la Real Just.a so pena [de] dies $\mathrm{p}^{\circ}$ s para la comunidad». Tres meses después, en vista de que algunos indios de Sunicancha se negaban a «obedecer» la real justicia y retirar sus animales, don Lorenzo Anchiñaupa elevó su petición al corregidor, quien lo amparó en sus tierras. Con mandamiento en mano, don Lorenzo se presentó esta vez ante el alcalde ordinario de Sunicancha, solicitando que se castigase a los culpables, en particular a una tal Catalina Cassaticlla,

${ }^{19}$ Ib., ff. 2r, 10r-v. 
quien había construido un corral para sus animales en tierras de don Lorenzo. ${ }^{20}$ En su auto de respuesta, firmado por el escribano de cabildo correspondiente, el alcalde mandó que Catalina fuese «bien castiga[da] y tresquelados sus cavellos con todo Regor de derecho». ${ }^{21}$ Como se ve, estos alcaldes no solo ejecutaban los autos de sus corregidores, sino que también emitían sus propios mandamientos, pronunciaban sentencias, ordenaban arrestos e imponían penas en nombre de la justicia regia y a favor del común. Como afirma el mandamiento de San Damián, los alcaldes eran esa real justicia.

\section{«ESTÁ ALLÍ EL MISMO RREY Y SEÑOR EN PERSONA»}

La vigencia de estas prácticas ofrece una puerta de entrada a dos aspectos centrales de la cultura legal de los pueblos de Huarochirí. ${ }^{22} \mathrm{El}$ primero es la autoridad que la vara de mando, símbolo del poder supremo del rey, confería a quienes la portasen (incluso si la detentaban temporal o, a los ojos de algunos, ilegítimamente). En palabras de Felipe Guaman Poma, donde estaban el alcalde, el regidor o el alguacil mayor, «está allí el mismo rrey y señor en persona». ${ }^{23}$ En efecto, los alcaldes de Huarochirí

${ }^{20}$ No deja de ser interesante que don Lorenzo, él mismo alcalde de San Damián, se presentase ante los alcaldes de Sunicancha. Aunque es claro que, desde la perspectiva de aquel dicho cabildo no tenía jurisdicción sobre sus tierras, quizá se pueda pensar que sí se la reconocía para castigar a los indios de Sunicancha que se negaban a abandonar los terrenos, como se verá enseguida. En otras palabras, puede que estos cabildos hayan combinado jurisdicciones sobre gentes y tierras en maneras en las que habría que profundizar.

21 "Martín Astorirayco y Cristóbal Paucarcaxa», ff. 24r-26r. Unos años antes, don Miguel Yauricaxa fue apresado y puesto en la cárcel pública de San Damián por cortar los árboles de quisuar de los indios del ayllu Concha, al parecer por el entonces alcalde del pueblo, don Lorenzo Anchiñaupa, del mismo ayllu, mencionado más arriba.

22 Por «cultura legal» entendemos el conocimiento popular/letrado del Derecho - $\mathrm{O}$ los «Derechos» en una perspectiva pluralista - y principalmente su uso social. Este uso social depende de las agendas políticas y jurídicas de cada colectivo humano. Los profesionales del mundo legal y los usuarios no especializados son los actores que redefinen las instituciones y los principios de esos órdenes jurídicos (Burbank 2004: 5-10; Cunill 2012: 392; y Yannakakis 2013: 931-947).

${ }^{23}$ Guaman Poma 1992: 505. 
formaban parte de los engranajes de la justicia real, encarnando además un poder vicario del poder del rey. Decoradas con casquillos de plata y adornadas con las armas reales y otros motivos (a veces religiosos), las varas que alcaldes mayores y ordinarios, alguaciles y regidores recibieron desde mediados del siglo XVI representaban la facultad de estos oficiales de república de dispensar justicia, exigir respeto y comandar obediencia en nombre de Su Majestad. Las varas también identificaban a quienes, por elección, nombramiento o comisión particular de virreyes, oidores o corregidores, quedaban autorizados para ejecutar, en la ciudad y en el campo, las órdenes, instrucciones y sentencias de los representantes del poder regio. $^{24}$

Este poder representacional de las varas caló muy hondo entre los pueblos de indios, donde, en el plano simbólico, las autoridades municipales pasaron a encarnar la voluntad de un rey distante de quien se decía que siempre hacía justicia. Para Felipe Guaman Poma, tanto el alcalde ordinario como el corregidor eran «justicias de Dios y de su Magestad». Por tanto, "Ni el uno al otro no le lleua uentaja». ${ }^{25}$ Precisamente, don Martín y don Cristóbal, de Sunicancha, acusaron a su rival, don Lorenzo Paullorayco, de haber usurpado la vara alta de la real justicia, aparentemente del alcalde de San Damián, quien lo acompañó durante la toma violenta de los terrenos de Huacaycocha pero desempeñó, al parecer, un papel secundario. Además de pedir compensación por los árboles talados, los dos principales de Sunicancha denunciaron que, aunque don Lorenzo era un principal como ellos, no había tenido "liçencia» para alzar la vara en aquella ocasión, presumiblemente porque no era miembro electo del cabildo ni había recibido comisión particular de los ministros del rey. Aunque otros «curacas» y "camachicos» del ayllu Concha estuvieron presentes, fue don Lorenzo quien, alzando la vara y penetrando con ella en los terrenos, dio la orden de tomar posesión. ${ }^{26}$

${ }^{24}$ Espinoza 1960: 202-204 y 1963: 46-48; y Guevara Gil y Salomon 1994: 17.

25 Guaman Poma 1992: 505-506, 779, 825.

26 "Martín Astorirayco y Cristóbal Paucarcaxa», f. 14r. Para el sistema de varas en las comunidades actuales de Huarochirí, véase Salomon 2004. Aunque es claro que existen muchas continuidades, hacen falta más investigaciones sobre este objeto ritual, el mismo 
Quizás el principal utilizara la autoridad de la vara para movilizar arbitrariamente a los miembros de su ayllu $y$ ordenarles que tomasen control de las tierras, incluso contra la voluntad colectiva. Más probable es que dicha voluntad grupal fuese uno de los actores ocultos de la causa. Don Lorenzo habría tomado la vara para sí —o esta le fue cedida por el alcalde, tal vez a pedido del común - con el fin de legitimar las acciones que el ayllu estaba a punto de emprender de acuerdo con su «mandato», garantizando así que la posesión de las tierras tuviera que entenderse como un acto de obediencia a Su Majestad, bajo el amparo de la real justicia. En ambos escenarios, se trasluce la necesidad de portar la «bara de su Magestad» para comandar el poder supremo, inmediato e incuestionable —aquello que otros testimonios califican como «la mano poderosa» de la justicia-, pero sobre todo para recibir el reconocimiento colectivo de la autoridad concentrada en la institución a la que el sistema de varas estaba estrechamente vinculado, el cabildo de naturales. ${ }^{27}$ Don Lorenzo era un curaca que, sin embargo, apeló a la vara para legitimar su autoridad judicial.

\section{GUARDIANES DE LA REAL JUSTICIA}

Un segundo aspecto que nos alerta de lo enraizadas que estaban estas prácticas de justicia en estas comunidades andinas es el uso experto del castellano judicial, caracterizado por un repertorio notable de formulismos legales que, aunque emanados originalmente de los grandes tribunales audienciales seculares y episcopales en donde ejercían su oficio innumerables procuradores de causas, fueron rápidamente adaptados a las necesidades andinas locales. ${ }^{28}$ Salvo contadas excepciones, los autos,

que vino a simbolizar, quizá más que ningún otro, el poder político y judicial en los Andes. La amplia literatura dedicada a las comunidades del Perú y del Alto Perú en el tumultuoso siglo XVIII así lo demuestra.

${ }^{27}$ Otros testimonios confirman la autoridad que los portadores de estas varas comandaban, así como el poder que ejercían, incluso si algunos lo consideraban ilegítimo o arbitrario. Por ejemplo, «Sumaria de la causa de capítulos contra don Bernardino de Perales», 1647. Archivo General de Indias [en adelante AGI], Lima, 100, ff. 6v-7r, 10v. ${ }^{28}$ Existe una bibliografía creciente al respecto: Garatea 2007; Vergara 2014, ambos dedicados al fiscal Agustín Capcha, así como el número monográfico de la revista Allpanchis 
peticiones, encabezados, informaciones de testigos, diligencias y otros recaudos propios de la primera etapa del litigio de 1637 — antes de que la causa se apelara ante la audiencia de Lima - fueron cuidadosamente redactados en esta retórica forense, además de firmados, rubricados y hasta enmendados por estos alcaldes y escribanos, así como por los mismos litigantes, ya fuera a título personal o en nombre de sus pueblos y ayllus. Los escribientes utilizaron una plétora de fórmulas tales como «De hecho y caso pensado", "para que cada uno de ellos aliguen ssu derecho", "que en ello reseberemos mrd con justi.a»y, por último, la resonante "Vmd como mi Justiçia debaxo de amparo mi haga justiçia que en Ello resebiremos mrd y gran justicia». Es también notoria la utilización de abreviaturas para términos que, se puede pensar, eran escritos con frecuencia por los escribanos de cabildo de Huarochirí, tales como «m[e] $\mathrm{r}[\mathrm{ce}] \mathrm{d}$ », «justi[ci]a» $\mathrm{o}$ «alc[a]ld[e]», así como rápidamente aprendidos por quienes les sucedían en el oficio. ${ }^{29} \mathrm{El}$ afianzamiento del cabildo de naturales como una corte de justicia a fines del siglo XVI estuvo signado por el nacimiento de esta variante escrita legal y vernácula, uno de los cimientos de la montaña letrada huarochirana, a la vez que metáfora lingüística para graficar los procesos de apropiación y transformación que se daban en la esfera más amplia de la interacción entre ley y sociedad. ${ }^{30}$

Este aspecto aún poco estudiado de la temprana historia legal andina desdibuja la frontera entre lo consuetudinario/popular y lo culto/oficial, poniendo en tela de juicio su valor como dicotomía analítica. La premisa de que el Derecho colonial fue principalmente construido y administrado por autoridades españolas y sus expertos legales en desmedro de los propios agentes indígenas es insuficiente, pues esconde su rol activo no solo como litigantes sino como intérpretes y arquitectos de su ordenamiento jurídico. La reformulación de viejos formulismos en los cabildos huarochiranos es la expresión visible de un proceso profundo

titulado «El español en los Andes coloniales: textos, autores y discursos», aparecido el año 2012. Para una revisión historiográfica más exhaustiva, véase Puente Luna 2016.

29 "Martín Astorirayco y Cristóbal Paucarcaxa», ff. 3r-8r, 18r-v.

${ }^{30}$ La referencia a la montaña letrada proviene, por supuesto, de Salomon y Niño-Murcia 2011. 
de reelaboración que sentó las bases para el surgimiento de una interlegalidad andina colonial.

Aunque conocemos poco todavía sobre la formación letrada de estos actores sociales en Huarochirí y los mecanismos formales e informales a través de los cuales se transmitían sus saberes legales, en el vecino valle de Jauja había ya procuradores informales calificados para escribir peticiones en español a pedido de litigantes indígenas reclamando tierras ante el corregidor sesenta ańos antes del pleito materia de este estudio. Estas transacciones generaban incontables situaciones propicias para la transmisión de tales saberes. ${ }^{31}$ Es probable, además, que los principales de estas localidades de la sierra central perteneciesen a ese mercado ávido de lectores que consumieron, directa o indirectamente, la llamada «literatura práctica». ${ }^{32}$ En particular, los manuales procesales, testamentarios y notariales (muchos de ellos impresos en Lima) contenían las herramientas necesarias para quienes necesitaran otorgar cartas, preparar testamentos, presentar peticiones y dirimir causas en estos juzgados municipales. ${ }^{33}$

${ }^{31}$ Para elaborar su reclamo de las tierras de Calpala en 1570, Martín Piçarro Guancallauqui, al parecer indio del común, recurrió a Bartolomé Díaz, clasificado como mestizo. Díaz redactó la petición en español que Martín presentó al corregidor, alegando que su abuelo y bisabuelo habían poseído la chacra por merced del Inca y desde «inmemorial tiempo a esta parte». «Residencia: Gabriel de Loarte», 1575. AGI, Justicia, 463, ff. 226v$227 \mathrm{v}$.

32 Respecto de la Curia Philipica de Juan de Hevia Bolaños, la cual trataba sobre los procedimientos judiciales civiles, Fernando de Montesinos escribió: «a hecho mucho dańo [...] en este Reyno, no por mala, sino por bien entendida; todos son letrados; especialmente los mestizos se inclinan a ésto [los pleitos] ya me dicen que los indios también tratan de esto y andan en sus pueblos amenaçando á los corregidores y curas con la Curia» (Montesinos 1906, II: 222). Agradecemos la referencia a Herman Barreto. Este consumo se extendía a las obras doctrinarias. En 1588, Bartolomé Álvarez, párroco de Andamarca, criticó la venta de Las Siete Partidas a litigantes indígenas (Platt 2014: 268). Don Juan Condorpusa, cacique del pueblo de La Chimba en Arequipa, poseía una copia de la Política Indiana de Juan de Solórzano, la cual consultó mientras trataba de asegurar una real provisión que eximiera a sus sujetos de la mita. "Carta. Don Juan Condorpussa a dońa María Fernández de Córdoba», Arequipa, 9 de noviembre de 1664. AGI, Lima, 171.

${ }^{33}$ Fuera del texto de Hevia, con numerosas reimpresiones entre 1603 y 1841 , la imprenta en Lima fue muy activa en la producción de material para uso forense y notarial, como 
Algunos textos quizá circularan parcialmente como modelos o cartas sueltas. ${ }^{34}$ La pluma experta de quienes participaron en la construcción del expediente de Huarochirí entre 1615 y 1637 sigue las pautas forenses del castellano judicial (las «leyes de estilo», en la terminología de la época), revelando, como la de sus pares en otras partes del imperio, un dominio mimético de la retórica y la práctica discursiva de la Ciudad Letrada. ${ }^{35}$

Un personaje que ejemplifica el perfil de estos gestores de la justicia regia es don Cristóbal Choquecasa quien, como se dijo, fue comisionado por el corregidor para fungir de juez y asesor durante la causa de 1637. La actuación del famoso cacique, segunda persona de los checas en este tipo de procesos, así como su pericia en los foros de justicia, eran el resultado de una larga carrera como litigante cuyos fragmentos hoy comienzan a salir a la luz. ${ }^{36}$ Choquecasa vivió a caballo entre la primera y la segunda generación de indígenas letrados, arbitristas, jueces y procuradores que, como Felipe Guaman Poma, litigó en foros civiles y eclesiásticos. ${ }^{37}$ Como estos litigantes, Choquecasa conocía, además, la importancia de contar con la protección de personajes influyentes en la corte que tuviesen acceso directo al virrey y a los jueces de la audiencia. ${ }^{38}$

manuales, formularios y hasta sermones referidos a la profesión legal (Barreto 2009; y Guibovich 2001: 179).

${ }^{34}$ En su Nueva corónica, por ejemplo, Guaman Poma incluye plantillas de amparos y testamentos, así como instrucciones sobre cómo elaborarlos (Harrison 2015).

35 Dueñas 2010; y Rappaport y Cummins 2012: 257.

${ }^{36}$ En 1608, Choquecasa redactó un apartamiento en la variante regional de la «lengua general» según el cual los indios de la guaranga de Chaucarima (asentados en Sunicancha) se retractaban de sus acusaciones contra el cura Francisco de Ávila. Choquecasa también tradujo la escritura al castellano. Sobre la vida y carrera de don Cristóbal y su relación con el Manuscrito quechua de Huarochirí, véanse Durston 2007 y 2014; y Puente Luna 2015. Jimmy Martínez Céspedes prepara una publicación en la que aporta nuevos datos sobre don Cristóbal, incluidos el año de su nacimiento (1577) y su desempeño como alcalde ordinario de San Damián (1610 y 1631) (Martínez Céspedes 2016).

${ }^{37}$ Charles 2007. En 1594, como nos recuerda Alcira Dueńas en su ensayo incluido en este volumen, Guaman Poma recibió comisión del juez de tierras para realizar las diligencias y fallar en un pleito por unos terrenos cerca de Huamanga (Pereyra 1997: 268).

${ }^{38}$ El trabajo inédito de Martínez Céspedes muestra que, en junio de 1621, don Cristóbal escribió a un sacerdote en Lima, probablemente un jesuita, pidiéndole que influyese en su designación como gobernador interino del cacicazgo de Huarochirí. Para sustentar su 
En abril de 1631, don Cristóbal recibió la petición inicial de Astoricra y Paucarcaxa, quienes acusaron a dos indios del ayllu Concha de usurpar los terrenos de Huacaycocha. En tanto teniente de su propio hijo, el alcalde de San Damián don Carlos Marcelo, Choquecasa presidió la elaboración de los autos y ordenó la realización de las diligencias en los meses siguientes. Luego de solicitar al otro alcalde que diera razón de la causa para proveer justicia, y por medio del escribano de cabildo, don Cristóbal citó a las partes contrarias, recibió las declaraciones de los testigos y emitió autos hasta que su hijo don Carlos tomó la posta en noviembre y sentenció la causa, como habían hecho otros alcaldes antes que él, «conforme la ley en su jusgado tribunal», es decir, en el cabildo de San Damián. ${ }^{39}$

Dos años después, y quizá estando ya en Lima, don Cristóbal recibió un poder general del cacique principal de Huarochirí para fenecer, ante la Audiencia y en nombre del común de la provincia, un pleito por unas tierras. ${ }^{40}$ En marzo de 1637, cerca de dos años y medio después, don Cristóbal estaba de nuevo en Lima, esta vez para dictar ante notario una donación a favor de su hijo don Carlos Marcelo, su sucesor en el cacicazgo principal de la guaranga de Checa del pueblo de San Damián y, como el padre, segunda persona de la provincia. ${ }^{41}$ La donación permite entender tanto las razones que llevaron al común de Huarochirí a conferirle un mandato de representación en 1633 cuanto la decisión del corregidor, en julio de 1637, de encomendarle las diligencias de la causa por los terrenos de Huacaycocha.

pedido, Choquecasa resalta la necesidad de cristianizar a los indios de su repartimiento, labor en la cual él mismo se había desempeñado, y señala que la misiva viaja a Lima en manos de su hijo y acompańada de «unos papeles míos para que V.P haziendome gran merced se ocupe a entretenerse por su coriosidad pues en ella ha[lla] rá V.P el muy poquito servicio que he hecho a dios nuestro señor» (Martínez Céspedes 2016).

39 «Martín Astorirayco y Cristóbal Paucarcaxa», ff. 3r-8r. El 19 de octubre de 1631, don Carlos Marcelo pronunció sentencia, adjudicando las chacras de Huacaycocha a don Martín y don Cristóbal (Ib., f. 6r). Posteriormente, los demandantes solicitaron «perpetuo silencio» a sus contrapartes y que el corregidor confirmara el auto y les diese "posesión» efectiva de las tierras, lo que se hizo en una ceremonia en Sunicancha (Ib., ff. 7v-8r).

${ }^{40}$ Puente Luna 2015: 143-147.

41 «Donación. Don Cristóbal Choquecassa a don Carlos Marcelo Canchoguaman», Lima, 9 de marzo de 1637. AGN, Protocolos Notariales [en adelante PN], 1858, ff. 150r-151v. 
En el documento, Choquecasa demuestra su conocimiento del complejo entramado de doctrinas jurídicas y prácticas consuetudinarias que sustentaban los derechos a la tierra en el Perú del siglo XVII, así como su habilidad para navegar esos órdenes legales en favor de quienes debían perpetuar su linaje. ${ }^{42}$ En el poder de 1637, Choquecasa se declaró «ya muy biexo» e identificó a don Carlos como su único hijo y, por tanto, heredero universal de los terrenos que poseía en el valle de Pariacha, a cuatro leguas de la ciudad de Lima, y que ahora donaba de su libre y espontánea voluntad, dando así origen a un acto jurídico válido. Luego de identificar las tierras y sus linderos, don Cristóbal eligió una de varias argumentaciones legales, asegurándose de establecer su dominio a través de la herencia y la posesión ininterrumpida "desde el tiempo del Ynga», ese mundo no siempre remoto anterior a la Conquista. La narrativa legal consolidaba su dominio, significando que nadie había cuestionado sus títulos sobre los bienes por un siglo o más. De acuerdo con la misma narrativa, su familia las había poseído sin solución de continuidad por cuatro generaciones, comenzando, en sentido inverso, por don Cristóbal, hasta llegar a su bisabuelo, Llanlli Poma. Aunque las tierras estaban hechas «çienaga y pantanos y llenas de carrizales y montes», su carácter yermo constituía prueba adicional de que nadie las había reclamado para sí. ${ }^{43}$ Solo dos días después, don Carlos Marcelo arrendó sus terrenos a Francisco Rendón Sarmiento, labrador y residente en Lima, por nueve años. Esta nueva escritura reiteró que, dado que los terrenos habían permanecido incultos desde «el tiempo del Ynga», Rendón no pagaría

42 Díaz Rementería 1990: 115-118; y Guevara Gil 1993: 158-168, 299-303.

43 "Donación. Don Cristóbal Choquecassa a don Carlos Marcelo Canchoguaman», 150r. La escritura se hizo en presencia del licenciado Jerónimo de Cabrera, abogado de la Real Audiencia, por lo que no se puede descartar una eventual asesoría. Don Cristóbal evitó afirmar que los terrenos le habían sido dados por el Inca, sabedor quizá de que, desde tiempos del virrey Toledo (o incluso antes) este podía ser un argumento para la desposesión. Si los Incas habían sido tiranos, sus cesiones de tierras eran inválidas. Se abría también la posibilidad de alegar que las tierras habían sido del Inca y no de indios y comunidades, por lo que eran dominio real y no privado (Díaz Rementería 1990: 107; y Herzog 2013: 312). 
el alquiler de 50 pesos anuales durante los primeros tres años, pero todas las mejoras pertenecerían al cacique-alcalde de San Damián. ${ }^{44}$

Estos documentos revelan las estrategias de líderes como Choquecasa para establecer posesión sobre estas tierras como propias y transferibles por vía de herencia, removiéndolas finalmente de la esfera de dominio comunal. ${ }^{45}$ Como muestra la causa posterior por los terrenos de Huacaycocha, sin embargo, dichas estrategias eran parte de un repertorio legal más amplio que codificaba otras prácticas sociales y universos normativos, y que hombres experimentados como Choquecasa también dominaban y podían poner en práctica dependiendo de los foros, las circunstancias y los intereses enfrentados en cada caso. La elección del viejo cacique como juez por parte del corregidor en julio de 1637, a pesar de que aquel no era parte del pleito ni oficial del cabildo en ese momento, era indicativa de la confianza del magistrado español en este tipo de destreza legal. Como se dijo, don Cristóbal se tomó su trabajo muy en serio: firmó y rubricó diferentes autos, realizó diligencias, citó a diferentes testigos, mandó se les recibiese información y firmó por aquellos que no sabían hacerlo, y hasta enmendó, de su puño y letra, los deslices de un menos ducho escribano de cabildo (un dato de por sí interesante para la historia de la construcción del Manuscrito Quechua de Huarochirí). La elección de Choquecasa como juez también se debió a la esperanza del magistrado de que su presencia y la de los alcaldes dotasen de legitimidad a un proceso que, para los diferentes actores locales, podía resolverse «justamente» de más de una forma. ¿Cuál era, pues, el contenido de la causa que Choquecasa y que los alcaldes tenían que dirimir y que demandaba la presencia de aquel como asesor letrado?

44 «Arrendamiento. Don Carlos Marcelo Canchoguaman a Francisco Rendón Sarmiento». Lima, 11 de marzo de 1637. AGN, PN, 1858, ff. 186r-187v.

${ }^{45}$ Es interesante que los documentos señalen que los terrenos lindaban con tierras de los indios de Chaclla, otro grupo huarochirano con enclaves productivos en diferentes pisos ecológicos (Spalding 1984: 48-49). 


\section{CURIA REGIS: EL CABILDO ES CORTE}

Juan de Hevia definía curia como «Corte, Ayuntamiento, Lugar donde es el Rey, y la cura del bien público, y asiste la espada de Justicia que le rige». Aunque por justicia Hevia y otros entendían dar a cada quien su derecho, para quienes blandieron la «espada» en el pleito por las tierras de Huacaycocha, aquella se mostraba particularmente elusiva. ${ }^{46}$ En realidad, el fallo final de la Audiencia de 1639 vino a destrabar un tenso equilibrio de fuerzas que, hasta ese momento, había impedido que la causa se resolviese a favor de alguna de las partes. Es probable que el despliegue de esas fuerzas y el resultado de la disputa — quién probaría finalmente su «derecho»— dependiera en cierta medida de estrategias, lealtades y acuerdos que se ventilaron fuera del proceso y que, por tanto, escapan al presente análisis.

A partir de lo que sabemos, sin embargo, se puede postular con Tamar Herzog que, ya para el tercer decenio del siglo XVII, la fluidez entre derechos «ancestrales» y derechos conferidos o confirmados por las autoridades del rey era una realidad en Huarochirí. Herzog propone que ambas fuentes de derechos podían considerarse ya como «intercambiables» o incluso «indistinguibles» para el siglo XVII. ${ }^{47}$ En este caso particular, sin embargo, se daba hasta cierto punto lo primero (si atendemos, por ejemplo, a los «títulos» y argumentos de los demandantes) pero no necesariamente lo segundo, precisamente porque la justicia local también estaba en manos de jueces indígenas, quienes manejaban

${ }^{46}$ Hevia Bolaños 1989: 2. Las Partidas alfonsinas retomaban la definición clásica del Derecho Romano imperial de los siglos II y III d.C.: «Iusticia tanto quiere dezir, como cosa, en que se encierran todos los derechos, de qual natura quier que sean. $\mathrm{E}$ los mandamientos de la Iusticia, e del derecho son tres. El primero es, que ome biua honestamente, quanto en si. El segundo, que non siga mal, nin daño a otro. El tercero, que dé su derecho a cada vno» (Las Siete Partidas 1985: Partida III, Título I, Ley 3). ${ }^{47}$ Herzog 2013: 305-306, 313, 319. Sobre la incorporación de la costumbre para el caso particular del Perú y Huarochirí, véanse, respectivamente, Díaz Rementería 1976: 189-190 y 1990: 111; y Spalding 1984: 45-46. Los ejemplos más tempranos sobre el uso, por caciques y sus procuradores, de discursos legales que combinaban invocaciones al Derecho castellano y al orden legal anterior a la llegada de los espańoles (i.e., «el tiempo de los Yngas») datan de 1552 (Honores 2015). 
diferentes registros legales. Aunque, como señala Herzog, el temprano reconocimiento de los derechos prehispánicos a la tierra conllevó una profunda e irreversible transformación de tales derechos, dichas transformaciones no siempre implicaron su eventual e inevitable absorción por los principios castellanos. Visto desde el ámbito de lo local, y dadas las profundas raíces agrarias de ambas sociedades, la ibérica y la andina, puede más bien que estemos ante un caso de coincidencia, coexistencia y adición antes que de substitución. En realidad, el reconocimiento oficial de diferentes normas consuetudinarias prehispánicas en la década de 1550 estableció las condiciones para la creación y reproducción de un espacio jurisdiccional en el que, en ciertos casos y dependiendo de actores y circunstancias específicas, diferentes ordenamientos podían ser invocados para legitimar los alegatos de las partes. En tal sentido, los cabildos de Huarochirí devinieron en un ejemplo paradigmático del proceso más amplio de formación de espacios interlegales y multinormativos durante la Edad Moderna. Aunque generalizada, esta dinámica era, en último término, local, y cuando las condiciones lo permitían, selectiva o estratégica.

En su sentido más básico, el pleito buscaba establecer control permanente sobre la tierra. A pesar de las alusiones al tiempo "ñaupa», el de los Incas, importantes cambios se escondían detrás de esta aparente continuidad. Como lo demuestra el mapa incluido en el expediente, los antecedentes más inmediatos del pleito se ceñían al período de reducción de los habitantes de Huarochirí en pueblos de indios. Hacia fines de la década de 1570 o comienzos de la década siguiente, el ayllu Concha fue trasladado media legua desde su antiguo asentamiento de Conchasica en el cerro San Cristóbal (en cuyas faldas estaban las tierras en litigio) hasta el nuevo pueblo de San Damián, epicentro de las narraciones contenidas en el Manuscrito Quechua de Huarochirí. Esta reubicación implicó que algunos de los terrenos muy cercanos al «pueblo viejo» de Conchasica, los cuales los Concha habían poseído, usado e irrigado por más de cuatro generaciones, se dejaran sin labrar y, al menos parcialmente, sin regar. Igual de importante, motivados por la profunda reorganización, algunos habitantes de la zona pasaron a considerar que las tierras estaban ahora en 
el pueblo de Sunicancha, el mismo que se asentaba en un cerro vecino, separado de San Damián por un arroyo, una quebrada y una serie de antiguos hitos y mojones divisorios. ${ }^{48}$

En diciembre de 1615, don Lorenzo Anchiñaupa, alcalde ordinario de San Damián, retomó el cultivo de papas y ocas en las parcelas de Conxorocaya. Pero, desde fines del siglo XVI, algunos indios de Sunicancha habían estado pastando sus ganados en esta misma zona, beneficiándose del agua que proveía un antiguo canal y construyendo corrales para guarecer a los animales. Cualesquiera que hayan sido los acuerdos que permitieron este estado de cosas, los mismos se agotaron ante la renovada demanda de los terrenos para la labranza. Don Lorenzo invocó un mandamiento del corregidor anterior y pidió al actual que emitiese una orden en que se señalase "graues penas» para los infractores y autorizase al alcalde "para que yo desbarate de su cor[r] al aunque limpe me sequia». Así, es probable que el acuerdo estuviera basado en la contribución de fuerza laboral a los propietarios del canal: los pastores ocupantes, convertidos ahora en transgresores, habían mantenido la acequia de los Concha a cambio del acceso a los pastos y terrenos eriazos, pero ahora el ganado amenazaba la futura cosecha y aquellos tenían que irse. ${ }^{49}$ Estas mismas contradicciones se repetirían veinte años después, cuando las autoridades de Concha decidieron reutilizar los terrenos para beneficio de la iglesia de su pueblo, San Damián. ${ }^{50}$

En el ínterin, otros residentes de Sunicancha, en particular los litigantes don Martín Astoricra y don Cristóbal Paucarcaxa, así como posiblemente sus ancestros y aliados, también ocuparían algunas de estas chacras (que llamaron o rebautizaron como "Huacaycocha»), ya fuese de facto o merced a acuerdos con los Concha que la documentación no explicita.

48 «Martín Astorirayco y Cristóbal Paucarcaxa», ff. 6r, 235r-v.

${ }^{49}$ En 1596, los originarios de algunos ayllus de Huarochirí poseían parcelas en áreas ocupadas por otros ayllus pero, para poder regarlas, necesitaban autorización de los ayllus «dueños» y poseedores de las acequias (Espinoza 1971: 164). Estos y otros acuerdos han sido documentados para la costa norte, cuyas poblaciones también dependían del riego (Ramírez 1987: 581-583).

50 "Martín Astorirayco y Cristóbal Paucarcaxa», ff. 10r, $24 \mathrm{v}$. 
A diferencia de otros ocupantes de Sunicancha, sin embargo, Astoricra y Paucarcaxa construyeron $s u$ propia acequia, la misma que, como se narra en la viñeta que abre este ensayo, los indios de Concha removerían en 1637 porque era capaz de establecer derechos sobre la tierra y sus productos. ${ }^{51} \mathrm{La}$ construcción del nuevo canal indica no solo la voluntad de los dos principales de Sunicancha de usufructuar los terrenos perennemente, sino también la participación de otros actores sociales, casi seguramente de Sunicancha, que permanecieron en el trasfondo del litigio.

Sea como fuere, la estrategia de los dos principales para posesionarse de los terrenos incluyó además otras medidas, como la ya mencionada presentación de una petición de amparo y de dos testigos favorables a su causa ante los alcaldes de San Damián en 1631. En su petición, expusieron dos argumentos familiares: la continua y pacífica posesión sobre esta chacra que habían ejercido sus antepasados y la usurpación que de ella querían hacer ahora dos indios de Concha, cuyos padres y abuelos nunca las habían sembrado. Aprovechando el sospechoso silencio de la parte contraria, Astoricra y Paucarcaxa acudieron al corregidor para que confirmase la sentencia favorable del alcalde de San Damián, ordenase que se les diese posesión e impusiese "perpituo selencio pues es justiçia». Haciendo explícita la "preocupación por la memoria» a que se refiere Herzog, los litigantes se preocuparon también por forjar una cadena de reconocimientos oficiales de sus títulos en los años siguientes. La misma convocó a dos nuevos corregidores y a un oidor de la Audiencia que pasaba por Huarochirí en 1636. Todos confirmaron la posesión con sendos títulos. ${ }^{52}$

\section{SEÑORES DEL AGUA}

Las diferentes causas judiciales, sin embargo, también llevan la huella de un universo de mecanismos alternativos, algunos de ellos de origen prehispánico, para resolver conflictos, desagraviar partes afectadas, establecer dominio y tomar posesión y control de recursos valiosos como

${ }^{51}$ Ramírez 1987: 581.

52 «Martín Astorirayco y Cristóbal Paucarcaxa», ff. 8r-9v; y Herzog 2013: 309. 
la tierra, los cultivos y sobre todo, el agua. ${ }^{53}$ Igual de importante, los derechos ancestrales a estas parcelas en disputa se sustentaban no solo en títulos sino en un "fondo de memoria» cuya lógica interna y criterios de verdad y legitimidad poco tenían que ver con los decretos obtenidos de los ministros del rey por los dos principales de Sunicancha. El capítulo 31 del Manuscrito Quechua, recopilado unos treinta ańos antes, describe esta fuente de recuerdo colectivo, así como a algunos de sus principales artífices y custodios, en clave genealógica y mítico-normativa. El texto narra las hazañas de Llacsamisa, ancestro y héroe mítico del ayllu Concha, quien desciende sobre el pueblo o llacta de Conchasica y ahuyenta a los yuncas que habitaban la zona (los llactayoc originales). Llacsamisa, sin embargo, casa a su hermana con el único indio yunca que permanece en Conchasica, accediendo así a los saberes agrícolas e hidráulicos de que dependía la utilidad de estas tierras. A través de esta alianza, Llacsamisa establece los títulos del ayllu Concha sobre bases consideradas legítimas en la lógica del manuscrito: un derecho de conquista antes de la Conquista. ${ }^{54}$

Con esta historia, los creadores del texto sustentaban y reconocían los derechos hereditarios de los Concha (descendientes de Llacsamisa y de sus cuatro "hermanos» menores) a la red hidráulica cuyo origen era la laguna de Yansa, a unos cinco kilómetros de San Damián. Estos derechos establecían, a su vez, la posesión de las tierras irrigadas y sus frutos. En efecto, las acciones de estos personajes mito-históricos fundamentaban la ley que reproducía el orden presente (el régimen intra e interpueblerino de riego) y que Llacsamisa, vuelto ahora camayoc o especialista del agua, solicitó y recibió directamente de los antiguos dueños del lago (los huacas Collquiri y Capyama). Collquiri le enseñó al héroe cómo dominar el agua: a represarla y canalizarla apropiadamente hasta un reservorio ubicado en la villa de Conchasica, del cual dependían otros menores, así como a distribuirla con justicia entre los poseedores de

${ }^{53}$ En los siguientes párrafos, seguimos de cerca los argumentos de Salomon 1998: 271-272. Sobre litigios por el control del agua y el sistema hidráulico en Huarochirí, Espinoza 1971: 161-162.

54 Taylor 2008: 129-141. 
las diferentes parcelas luego de las lluvias. ${ }^{55}$ En este paraje, así como en otros de Huarochirí, diferentes actividades rituales movilizaban este cuerpo de tradiciones y saberes anualmente con motivo de la limpia de las acequias y la liberación progresiva del agua. Los ritos rememoraban el régimen aprendido de los antiguos dueños del lago para irrigar los campos y reproducían los derechos hereditarios y el sistema de poder que se reflejaban en la infraestructura que brotaba de Yansa, la laguna del ayllu Concha. ${ }^{56}$

Este régimen era la costumbre en Huarochirí cuando el famoso compendio de ritos y tradiciones fue preparado hacia 1608. Significativamente, el texto quechua usa el término castellano para referirse al conocimiento y la autoridad que Llacsamisa recibió de Collquiri y que sus descendientes decían seguir fielmente hasta entonces. ${ }^{57}$ El lenguaje de la costumbre proveía, como en otras partes, un medio para afirmar o alterar el statu quo pero presentándolo, en ambos casos, como inmutable. ${ }^{58} \mathrm{El}$ manuscrito fue la creación de estos guardianes de la costumbre, informantes y recopiladores del ayllu Checa, reducido en San Damián junto a los Concha, sus rivales y complementarios rituales. $\mathrm{Al}$ ayllu Checa pertenecieron, además, algunos jueces de la causa de 1631-1637, como los ya citados don Cristóbal Choquecasa y su hijo don Carlos Marcelo Canchoguaman.

Como se recordará, además, los principales y camachicos don Lorenzo Paullorayco y don Lorenzo Anchiñaupa, lideraron la batalla legal del ayllu Concha de San Damián en su momento. ${ }^{59}$ Es evidente su conocimiento, así como el de los principales, alcaldes y escribanos de Sunicancha que desfilan por la causa, de las tradiciones de Conchasica y otras análogas, además de la conciencia que tenían del potencial

\footnotetext{
${ }^{55}$ El uso de camayo para referirse a los oficiales encargados del cuidado del agua de riego está documentado ya en un pleito que, por su fecha tan temprana (1539), ciertas comunidades de la costa norte litigaron ante la audiencia de Panamá (Ramírez 1987: 582).

${ }^{56}$ Salomon 1998: 265-268; Spalding 1984: 36; y Taylor 2008: 129-141.

57 Taylor 2008: 136.

${ }^{58}$ Graubart 2007: 158-195; Premo 2014; y Yannakakis 2010.

${ }^{59}$ La relación de Dávila Briceño define a los «camachicos» como «cabezas de parentelas y de pueblesuelos antiguos» (Jiménez de la Espada 1881, I: 67).
} 
valor instrumental de estas narrativas en la endémica competencia por tierras y recursos. ${ }^{60}$ La decisión de estos líderes de recodificar algunas de estas historias para volcarlas en el registro legal (en su versión secular, por supuesto) quedó atestiguada una vez que el conflicto escaló hasta convertirse en una causa entre Concha y Sunicancha por las aguas y lomas de Yanascocha, seguida aún ante la Audiencia en 1650. ${ }^{61}$

Como aclara el manuscrito para comienzos del siglo XVII, algunos linajes patrilineales habían heredado los antiguos cargos, privilegios y responsabilidades de los sacerdotes-jueces que, como en el caso de otras autoridades comunales, se beneficiaban del trabajo colectivo de sus ayllus a cambio de sus servicios rituales y, podemos agregar, funciones administrativas y judiciales. ${ }^{62}$ En el plano general, la Nueva corónica los llama «asecya alguacil», identificando apropiadamente a estos jueces de aguas también como justicias de Su Majestad. ${ }^{63}$ Un litigio de 1596 por el uso de la acequia de Marhuaca en Huarochirí alude a las actividades de algunos de estos especialistas del agua, curacas, alcaldes y otros oficiales subordinados, quienes se ocupaban de coordinar la inspección, mantenimiento y mejoramiento de canales y bocatomas (considerados propiedad comunal), además de la distribución del recurso por turnos y segmentos (entre los miembros

${ }^{60}$ Historias similares a la de Llacsamisa y el ayllu Concha, referidas al establecimiento de derechos hidráulicos, aparecen en los capítulos 6 y 7 para el ayllu de Cupara y en el capítulo 30 para el de Allauca (Taylor 2008: 43-45, 127). El agua es uno de los grandes temas del manuscrito.

${ }^{61}$ Durston 2014: 163-164; Salomon 1998: 273-276; Salomon 2003: 267; y «Martín Astorirayco y Cristóbal Paucarcaxa», f. 229r y ss.

62 Taylor 2008: 141. En distintos puntos, el manuscrito describe los cultos asociados a lagos y manantiales, así como los roles de los sacerdotes (yañcas y huacsas), algunos de ellos, especialistas del agua. Sobre el rol judicial de estos yañcas, véase Spalding 1984: 65-67.

${ }^{63} \mathrm{Al}$ parecer dependiente de los alcaldes de campo, este «alguacil de la secya» tenía, entre sus tareas, por las cuales recibía un salario de los fondos comunales y del quinto real, repartir «la agua de rregar a la yglecia, cofrade, comunidad sapci, al cacique principal, a los mandones, a la justicia, a los tributarios, biejos, enfermos, pasados, biudas, güérfanos, forasteros cin hazello agrauio a yadie [sic: nadie]» (Guaman Poma 1992: 833). 
de una parcialidad y entre parcialidades) y la resolución de conflictos; en suma, de hacer respetar la costumbre que reglamentaba el uso. ${ }^{64}$

Hacia fines de la década de 1570, algunas funciones consuetudinarias habían pasado a ser ejercidas en el ámbito institucional del cabildo de naturales. ${ }^{65}$ En Huarochirí, y quizá en otras partes, el concejo pasó a albergar a los curacas y camachicos, antiguos conocedores del orden legal tradicional y, por tanto, detentadores de la ley y la justicia, articulando a estas autoridades con el nuevo sistema de cargos electivos y rotativos. De hecho, las ordenanzas toledanas asignaban a «caciques y principales, alcaldes y regidores» la tarea de construir, reparar y aderezar las acequias y fuentes, facilitando así la superposición mimética de cargos y funciones. ${ }^{66}$

Como se ha dicho, estos oficiales conocían la cultura legal española y participaron en la génesis de una cultural legal colonial. El punto a resaltar aquí, sin embargo, es que, como lo demuestra el Manuscrito Quechua de Huarochirí, jueces y autoridades custodiaban también otras esferas normativas que, como la historia de Llacsamisa, se desprendían del mito y el rito (lo cual no significa, por supuesto, que tuvieran que fallar siempre de acuerdo con ellas). Para quienes actuaban según la lógica de estas otras esferas codificadas en el Manuscrito, el orden jurídico castellano no siempre proveía un equivalente, una respuesta o un fallo considerados «justos» en el microcosmos de la comunidad. La elección del Derecho castellano tampoco debió representar siempre la opción más estratégica.

Resulta, pues, muy plausible que este cúmulo de tradiciones referidas a acequias, chacras y mojones (todos ellos con nombres propios e histo-

${ }^{64}$ Espinoza 1971: 165; y Spalding 1984: 66. Salomon resalta la conexión etnográfica entre presidentes y varayocs actuales y los antiguos sacerdotes (1998: 281-283). El material etnográfico corrobora esta antigua relación entre el sistema de autoridades y el sistema hidráulico en Huarochirí.

${ }^{65}$ Una de las menciones más tempranas a la jurisdicción de los alcaldes de las parroquias de naturales del Cuzco celebra su habilidad para finiquitar, «sin figura de juicio», los pleitos por tierras, aguas y montes (Memorial 1889).

${ }^{66}$ Sarabia Viejo 1986-1989, II: 247. El papel de los caciques como jueces en diferentes materias se discute en Graubart 2015: 221; y Ramírez 2005. Es relevante también la discusión ofrecida por Felipe Guaman Poma de los sayua checta suyoyoc, jueces amojonadores y repartidores de chacras, pastos y acequias (Guaman Poma 1992: 355). 
rias anclados en el paisaje local), el cual servía para discernir derechos y mantener una tensa paz, se activase y vertiese también en algunas querellas atendidas por los jueces indígenas del cabildo, oralmente o por escrito. Las historias que allí ponderaban los jueces cuando "hacían cabildo", o las que recogían de los testigos in situ, quizá no fuesen muy distintas de las que se contaron en el Manuscrito de Huarochirí. Este universo normativo tińó las acciones de los litigantes y las decisiones de los jueces en la serie de causas por las tierras de Huacaycocha, aunque aquí solo sea posible delinear los contornos de esa influencia. ${ }^{67}$

Frank Salomon ha resaltado ya los tintes rituales de los desafíos y enfrentamientos narrados al inicio de este artículo —en particular, el rapto de las mujeres de los demandantes en el pueblo viejo de Conchasica y el intercambio de injurias-, así como la clara alusión a los tiempos pretéritos en que, a través de la guerra, la conquista y la diplomacia, los antepasados de los litigantes establecieron y legitimaron su dominio sobre las tierras de los yuncas con el apoyo de Tupa Inca Yupanqui y de los huacas que poblaban el paisaje. ${ }^{68}$ Los capítulos levantados contra don Lorenzo Paullorayco muestran que algunas de las acciones del ayllu Concha, como el arrebatarle las llicllas a las mujeres de Sunicancha y quebrarles sus topos, se entendieron como ajenas a la esfera de poder de la vara real. Según los demandantes, «los yndios cumplieron su mandato

${ }^{67}$ En octubre de 1637, acompañado de los litigantes de Concha y Sunicancha, el teniente de corregidor se desplazó desde San Damián hasta Sunicancha, convocando a las partes para identificar sus mojones y examinar a los "yndios antiguos». El teniente se percató rápidamente de que los ancianos de ambas parcialidades tenían versiones distintas acerca de a quién pertenecían los terrenos y cuáles eran los mojones que los delimitaban. Aunque se inclinó por favorecer a los de Concha, el teniente se dio por vencido: «ay poco que hazer casso en los juramentos de unos y otros yndios antiguos de ambos pueblos» («Martín Astorirayco y Cristóbal Paucarcaxa», ff. 27r-30r).

${ }^{68}$ Espinoza 1983-1984: 157-163; Moore 1978: 41-46; Salomon 1998: 271-272; 2003: 253-254; y Spalding 1984: 80-81. La descripción de 1586 del repartimiento de Lucanas-Laramatis refiere que «ántes que los Ingas señoreasen esta tierra, traian guerra y diferencias los unos con los otros sobre las tierras de sementeras y pastos de sus ganados, y que peleaban con guaracas, que son hondas, y con otros que llaman champis, que es como maza de armas; y que despues que el Inga los sujetó no tubieron guerra entre si» (Jiménez de la Espada 1881, I: 189). 
de su curaca [...] desiendo que no balía El corregidor ni el Virrey». Otros elementos saltan a la vista, como la tradición de enviar mensajeros (cachas) con recaudos, información y presentes, tal y como la practicaban los antiguos señores de Huarochirí. ${ }^{69}$

También resulta indicativo que los indios de Concha citasen a los litigantes de Sunicancha a la pampa de Antacallua, pues las pampas eran espacios tradicionales de política, negociación y resolución de conflictos. Allí, si otros mecanismos fallaban, quizá terminarían enfrentándose como los héroes y curacas antiguos, recreando así las hazañas del tiempo, los dioses y los hombres que daban sentido a la costumbre. ${ }^{70}$ Es probable, finalmente, que curacas como Paullorayco, quienes parecían reclamar las tierras para sí pero también para el común de Concha y el culto religioso, estuviesen satisfaciendo algunas de las funciones rituales tradicionales que, en tanto jueces y administradores del agua revestidos ahora con la vara del poder real, el resto del ayllu demandaba de ellos. La orden de destruir la acequia de los rivales para montar una propia, quizá el acto central en el rito alternativo de posesión que se narra al inicio de este ensayo, podría estar indicándolo así. Como ha señalado Salomon, la frontera entre guerra y agricultura se revelaba flexible en Huarochirí. ${ }^{71}$ Pero la disputa demuestra no solo que una no necesariamente anulaba la otra, sino que no se excluían entre sí. Estas no se concebían siempre como parte de órdenes normativos distintos. Ambas quedaban más bien contenidas en la «ley» tal y como los dioses y héroes se la enseñaron a sus descendientes.

\section{CONCLUSIÓN}

La reconfiguración colonial del Derecho consuetudinario forma parte de varias experiencias históricas coloniales. ${ }^{72}$ Los alcaldes de los pueblos

\footnotetext{
${ }^{6}$ Salomon 2003: 264-268; y «Martín Astorirayco y Cristóbal Paucarcaxa», f. 14r-v.

${ }^{70}$ Salomon 1998: 271. Durante un pleito independiente de 1588, don Jerónimo Canchoguaman — padre de Choquecasa - recordó lo que sus mayores le contaron sobre las relaciones entre los diferentes ayllus y sus líderes: en las pampas "se juntaban los yndios [...] para tratar sus negoçios» (Salomon 2003: 264-265).

${ }^{71}$ Salomon 1998: 272.

72 Chanock 1998; Moore 1986; y Nader 1990.
} 
de indios fueron agentes centrales en este proceso tal y como se dio en los Andes. En su calidad de autoridades reales, hicieron uso de las atribuciones judiciales que les confería ese poder; la justicia real que gestionaron era un pilar del poder mayestático que ellos encarnaban en las Indias. El cabildo de naturales se gestó como una corte judicial con características propias, un escenario de discusión, negociación y selección de ideas legales. Los propios jueces y litigantes guiaron este proceso en la esfera local. A través de sus escritos, desarrollaron discursos jurídicos y prácticas procesales, en parte inspirados en la retórica legal de las altas cortes de justicia del Derecho civil y canónico. Este espacio judicial y la actividad de sus agentes y usuarios fueron cruciales en la construcción del Derecho colonial, una mixtura de varias tradiciones legales construida también «desde abajo».

Este proceso puede (y quizá deba) estudiarse en el contexto local, a partir de una lectura que tome en cuenta la historia, la geografía y los órdenes mítico-jurídicos de las comunidades en su experiencia previa a la Conquista. Las disputas expresaban las enormes tensiones y diferencias en los pueblos y entre ellos. Estos enfrentamientos, producidos por los reacomodos de los siglos XV y XVI, durante la dominación incaica y española, pueden apreciarse en el caso de Huarochirí. El ayllu Concha tenía una larga tradición de manejo de recursos hídricos en la zona que fue parcialmente interrumpida por su relocalización durante el proceso de reducción. Aunque la disputa giraba en torno a las tierras, la misma tenía como trasfondo la discusión sobre el control y uso de los recursos hídricos y su justificación a partir de los órdenes normativos en juego. El ejemplo analizado en este ensayo muestra la urgencia de repensar el binomio tierra/agua, evitando así una lectura muy literal de las formulaciones retóricas de los litigantes. El caso dirimido por los alcaldes de San Damián permite descubrir también las agendas de los litigantes y el rol de los alcaldes, pero sobre todo la gestación de discursos y prácticas legales que cimentaron el orden normativo complejo y plural de la justicia local en los siglos posteriores. 


\section{BIBLIOGRAFÍA}

Barreto, Herman. 2009. "Legal Culture and Argumentation in the Vice-Reign of Peru from the 16th to the 18th Centuries». Clio and Themis. Núm. 2. Disponible en: <http://www.cliothemis.com/Legal-Culture-and-Argumentation-in>. Belmessous, Saliha (ed.). 2012. Native Claims: Indigenous Law against Empire, 1500-1920. Oxford; Nueva York: Oxford University Press.

Black, Chad. 2010. The Limits of Gender Domination: Women, the Law, and Political Crisis in Quito, 1765-1830. Albuquerque: University of New Mexico Press.

Blockmans, Willem Pieter; Holenstein, Andrés y Jon Mathieu. 2009. Empowering Interactions: Political Cultures and the Emergence of the State in Europe, 13001900. Farnham/Burlington: Ashgate.

Brendecke, Arndt. 2012. Imperios e información: funciones del saber en el dominio colonial español. Madrid: Iberoamerica-Vervuert.

Burbank, Jane. 2004. Russian Peasants Go to the Court. Legal Culture in the Countryside, 1905-1917. Bloomington: Indiana University Press.

Burns, Kathryn. 2011. «Making Indigenous Archives: The Quilcaycamayoc of Colonial Cuzco». Hispanic American Historical Review. Vol. 91, núm. 4: 665-689. https://doi.org/10.1215/00182168-1416666

Calabria, Antonio y John A. Marino. 1990. «Introduction: Good Government in Naples?». En Calabria, Antonio y John A. Marino (eds.). Good Government in Spanish Naples. Nueva York: P. Lang, 1-12.

Cañeque, Alejandro. 2004. The King's Living Image: The Culture and Politics of Viceregal Power in Colonial Mexico. Nueva York: Routledge. https://doi. org/10.4324/9780203326930

Cardim, Pedro (ed.). 2012. Polycentric Monarchies: How Did Early Modern Spain and Portugal Achieve and Maintain a Global Hegemony? Brighton: Sussex Academic Press.

Chanock, Martin. 1998. Law, Custom, and Social Order: The Colonial Experience in Malawi and Zambia. Portsmouth: Heinemann.

Charles, John. 2007. "More Ladino than Necessary': Indigenous Litigants and the Language Policy Debate in Mid-Colonial Peru». Colonial Latin American Review. Vol. 16, núm. 1: 23-47. https://doi.org/10.1080/10609160701335891

Cunill, Caroline. 2012. "La negociación indígena en el Imperio ibérico: aportes a su discusión metodológica». Colonial Latin American Historical Review. Vol. 21, vol. 3: 391-412. https://doi.org/10.1080/10609164.2012. 730664

Díaz Rementería, Carlos. 1976. «La costumbre indígena en el Perú hispánico». Anuario de Estudios Americanos. Vol. 33: 189-215.

Díaz Rementería, Carlos. 1990. «El patrimonio comunal indígena: del sistema incaico de propiedad al de derecho castellano». En Levaggi, Abelardo (ed.). El 
aborigen y el derecho en el pasado y el presente. Buenos Aires: Universidad del Museo Social Argentino, 105-139.

Dueñas, Alcira. 2010. Indians and Mestizos in the "Lettered City»: Reshaping Justice, Social Hierarchy, and Political Culture in Colonial Peru. Boulder: University Press of Colorado.

Durston, Alan. 2007. «Notes on the Authorship of the Huarochirí Manuscript». Colonial Latin American Review. Vol. 16, núm 2: 227-241. https://doi. org/10.1080/10609160701644516

Durston, Alan. 2014. «Cristóbal Choquecasa and the Making of the Huarochirí Manuscript». En Ramos, Gabriela y Yanna Yannakakis (eds.). Indigenous Intellectuals: Knowledge, Power, and Colonial Culture in Mexico and the Andes. Durham/Londres: Duke University Press, 151-169. https://doi. org/10.1215/9780822376743-008

Duve, Thomas. 2013. «European Legal History - Global Perspectives». Colloquium 'European Normativity - Global Historical Perspectives', Max-PlanckInstitute, Berlín. Disponible en: <http://papers.ssrn.com/sol3/papers. cfm?abstract_id=2292666>.

Espinoza, Waldemar. 1960. «El alcalde mayor indigena en el virreinato del Perú». Anuario de Estudios Americanos. Vol. 17: 183-300.

Espinoza, Waldemar. 1963. «La guaranga y la reducción de Huancayo: tres documentos inéditos de 1571 para la etnohistoria del Perú». Revista del Museo Nacional. Vol. 32: 8-80.

Espinoza, Waldemar. 1971. «Agua y riego en tres ayllus de Huarochirí (Perú) siglo XV y XVI». Revista del Museo Nacional. Vol. 37: 147-166.

Espinoza, Waldemar. 1983-1984. «Los señoríos de Yaucha y Picoy en el abra del medio y alto Rimac». Revista Histórica. Vol. 34: 157-259.

Garatea, Carlos. 2007. «El español de un fiscal eclesiástico del siglo XVII». Lexis. Vol. 31, núms. 1-2: 131-150.

Graubart, Karen. 2007. With our Labor and Sweat: Indigenous Women and the Formation of Colonial Society in Peru, 1550-1700. Stanford: Stanford University Press.

Graubart, Karen. 2015. «Learning from the Qadi: The Jurisdiction of Local Rule in the Early Colonial Andes». Hispanic American Historical Review. Vol. 95, núm. 2: 195-228. https://doi.org/10.1215/00182168-2870764

Graubart, Karen. 2016. "Competing Spanish and Indigenous Jurisdictions in Early Colonial Lima». Latin American History: Oxford Research Encyclopedias. https:// doi.org/10.1093/acrefore/9780199366439.013.365

Guaman Poma, Felipe. 1992. El primer nueva corónica y buen gobierno. Tercera edición. México, D. F.: Siglo Veintiuno.

Guevara Gil, Armando. 1993. Propiedad agraria y derecho colonial: los documentos de la hacienda Santotis, Cuzco (1543-1822). Lima: Pontificia Universidad Católica del Perú. 
Guevara Gil, Armando. 2011. El derecho y la gestión local del agua en Santa Rosa de Ocopa, Junín, Perú. Lima: ARA Editores.

Guevara Gil, Armando y Frank Salomon. 1994. «A «Personal Visit: Colonial Political Ritual and the Making of Indians in the Andes». Colonial Latin American Review.Vol. 3, núms. 1-2:3-36. https://doi.org/10.1080/10609169408569822 Guevara Gil, Armando y Joseph R. Thome. 2009. «Apuntes Sobre el Pluralismo Legal». En Guevara Gil, Armando (ed.). Diversidad y complejidad legal. Aproximaciones a la Antropología e Historia del Derecho. Lima: Pontificia Unievrsidad Católica del Perú, 29-59.

Guibovich, Pedro. 2001. "The Printing Press in Colonial Peru: Production, Process and Literary Categories in Lima, 1584-1699». Colonial Latin American Review. Vol. 10, núm 2: 167-188. https://doi.org/10.1080/ 10609160120093769

Hanke, Lewis y Celso Rodríguez. 1978. Los virreyes españoles en América durante el gobierno de la Casa de Austria: Perú. Madrid: Atlas, 6 vols.

Harrison, Regina. 2015. «Guaman Poma, Law, and Legacy». En Adorno, Rolena e Ivan Boserup (eds.). Unlocking the Doors to the Worlds of Guaman Poma and His Nueva corónica. Copenhague: Museum Tusculanum Press, 141-161.

Herzog, Tamar. 2004. Upholding Justice: Society, State, and the Penal System in Quito (1650-1750). Ann Arbor: University of Michigan Press. https://doi. org/10.3998/mpub.17644

Herzog, Tamar. 2013. «Colonial Law and 'Native Customs': Indigenous Land Rights in Colonial Spanish America». The Americas. Vol. 69, núm 3: 303-321. https:// doi.org/10.1017/s0003161500002303

Hevia Bolaños, Juan de. 1989. Curia Philipica. Valladolid: Lex Nova.

Honores, Renzo. 2015. «Law, Rhetoric and Strategy in the Early Andean Litigation, 1552-1574». Ponencia presentada en el congreso anual de la American Historical Association, Nueva York, 2-5 de enero de 2015.

Jiménez de la Espada, Marcos. 1881. Relaciones geográficas de Indias. Perú. Madrid: Tipografia de Manuel G. Hernández, 4 vols.

Kagan, Richard L. 1981. Lawsuits and Litigants in Castile, 1500-1700. Chapel Hill: University of North Carolina Press.

Las Siete Partidas. Glosadas por el Licenciado Gregorio López. 1985. Madrid: Boletín Oficial del Estado, 3 vols.

Levillier, Roberto. 1921-1926. Gobernantes del Perú, cartas y papeles, siglo XVI. Madrid: Sucesores de Rivadeneyra, 14 vols.

Martínez Céspedes, Jimmy. 2016. “Cristóval Choquecassa’ y la extirpación de las idolatrías: una aproximación a la autoría del Manuscrito Quechua de Huarochirí (1577-1637)». Tiempos. Vol. 11, núm. 11 [en prensa]. 
«Memorial para el buen asiento y gobierno del Perú». 1889. En Colección de documentos inéditos para la historia de España. Madrid: Viuda de Calero, Vol. 94, 164-225.

Montesinos, Fernando de. 1906. Anales del Perú. Lima: Imp. de Gabriel L. y del Horno, 2 vols.

Moore, Sally Falk. 1978. Power and Property in Inca Peru. Westport: Greenwood Press.

Moore, Sally Falk. 1986. Social Facts and Fabrications: "Customary» Law on Kilimanjaro, 1880-1980. Cambridge: Cambridge University Press.

Mumford, Jeremy. 2012. Vertical Empire: The General Resettlement of Indians in the Colonial Andes. Durham: Duke University Press. https://doi.org/ $10.1017 / \mathrm{s} 0003161500002303$

Nader, Laura. 1990. Harmony Ideology: Justice and Control in a Zapotec Mountain Village. Stanford: Stanford University Press.

Navarro Gala, Rosario. 2015. El libro de protocolo del primer notario indígena (Cuzco, siglo XVI). Cuestiones filológicas, discursivas y de contacto de lenguas. Madrid/ Frankfurt: Iberoamericana/Vervuert.

Pereyra, Nelson. 1997. «Un documento sobre Guaman Poma de Ayala existente en el Archivo Departamental de Ayacucho». Histórica. Vol. 21, núm. 2: 261-270.

Pérez Landero, Pedro. 1696. Práctica de visitas y residencias apropiadas a los Reynos del Perú y deducido de lo que en ello se estila. Nápoles: Nicolás Layno.

Platt, Tristan. 2014. "Conclusion». En Ramos, Gabriela y Yanna Yannakakis (eds.). Indigenous Intellectuals. Knowledge, Power, and Colonial Culture in Mexico and the Andes. Durham: Duke University Press, 261-277. https://doi. org/10.1215/9780822376743-012

Premo, Bianca. 2005. Children of the Father King: Youth, Authority, \& Legal Minority in Colonial Lima. Chapel Hill: University of North Carolina Press.

Premo, Bianca. 2014. "Custom Today: Temporality, Customary law, and Indigenous Enlightenment». Hispanic American Historical Review. Vol. 94, núm. 3: 355-379. https://doi.org/10.1215/00182168-2694291

Puente Luna, José Carlos de la. 2015. "Choquecasa va a la audiencia: cronistas, litigantes y el debate sobre la autoría del Manuscrito quechua de Huarochirí». Histórica. Vol. 39, núm. 1: 139-158.

Puente Luna, José Carlos de la. 2016. «En lengua de indios y en lengua española’: cabildos de naturales y escritura alfabética en el Perú colonial». En Izquierdo, Ana Luisa (ed.). Visiones del pasado. Reflexiones para escribir la historia de los pueblos indigenas de América. Mexico, D. F.: Universidad Autónoma de México, 51-113.

Ramírez, Susan E. 1987. «The 'Dueño de Indios': Thoughts on the Consequences of the Shifting Bases of Power of the 'Curaca de los Viejos Antiguos' under the 
Spanish in Sixteenth-Century Peru». The Hispanic American Historical Review. Vol. 67, núm. 4: 575-610. https://doi.org/10.2307/2516045

Ramírez, Susan. 2005. «Amores prohibidos: The Consequences of the Clash of Juridical Norms in Sixteenth-Century Peru». The Americas. Vol. 62, núm. 1: 47-63. Rappaport, Joanne y Thomas Cummins. 2012. Beyond the Lettered City: Indigenous Literacies in the Andes. Durham: Duke University Press. https://doi. org/10.1215/9780822394754

Ross, Richard J. y Philip J. Stern. 2013. «Reconstructing Early Modern Notions of Legal Pluralism». En Benton, Lauren A. y Richard J. Ross (eds.). Legal Pluralism and Empires, 1500-1850. Nueva York: New York University Press, 109-141. https://doi.org/10.18574/nyu/9780814771167.003.0005

Rostworowski, María. 1975. "Algunos comentarios hechos a las Ordenanzas del doctor Cuenca». Historia y Cultura. Vol. 9: 119-154.

Salomon, Frank. 1998. "Collquiri's Dam: The Colonial Re-Voicing of an Appeal to the Archaic». En Boone, Elizabeth Hill y Thomas Cummins (eds.). Native Traditions in the Postconquest World. Washington, D. C.: Dumbarton Oaks, 265-293.

Salomon, Frank. 2003. "Testimonios en triángulo: personajes de la Nueva corónica de Guaman Poma y del manuscrito quechua de Huarochirí en el pleito sobre el cacicazgo principal de Mama (1588-1590)». Chungara. Vol. 35, núm. 2: 253-268. https://doi.org/10.4067/s0717-73562003000200005

Salomon, Frank. 2004. The Cord Keepers: Khipus and Cultural Life in a Peruvian Village. Durham: Duke University Press. https://doi.org/10.1215/9780822386179

Salomon, Frank y Mercedes Niño-Murcia. 2011. The Lettered Mountain: A Peruvian Village's Way with Writing. Durham: Duke University Press. https://doi. org/10.1215/9780822394341

Santos, Boaventura de Sousa. 1987. «Law: A Map of Misreading. Toward a PostModern Conception of Law». Journal of Law and Society. Vol. 14, núm. 3: 279-302. https://doi.org/10.2307/1410186

Sarabia Viejo, María Justina. 1986-1989. Francisco de Toledo: disposiciones gubernativas para el Virreinato del Perú. Sevilla: Escuela de Estudios Hispano-Americanos y Consejo Superior de Investigaciones Científicas, 2 vols.

Spalding, Karen. 1984. Huarochirí, An Andean Society under Inca and Spanish Rule. Stanford: Stanford University.

Spalding, Karen. 2015. «Notes on the Formation of the Andean Colonial State». En Krupa, Christopher y David Nugent (eds.). State Theory and Andean Politics: New Approaches to the Study of Rule. Filadelphia: University of Pennsylvania Press, 213-233. https://doi.org/10.9783/9780812291070-010

Taylor, Gérald (ed.). 2008. Ritos y tradiciones de Huarochirí. Lima: Instituto Francés de Estudios Andinos, Instituto de Estudios Peruanos y Universidad Nacional Mayor de San Marcos. 
Vergara, Teresa. 2014. «Evangelización, hispanización y poder: Agustín Capcha, fiscal mayor del Arzobispado de Lima». Nueva Corónica. Vol. 3: 109-123.

Yannakakis, Yanna. 2010. «Costumbre: A Language of Negotiation in EighteenthCentury Oaxaca». En Ruiz Medrano, Ethelia y Susan Kellogg (eds.). Negotiation within Domination: New Spain's Indian Pueblos Confront the Spanish State. Boulder: University Press of Colorado, 137-171.

Yannakakis, Yanna. 2013. "Indigenous People and Legal Culture in Spanish America». History Compass. Vol. 11, núm. 11: 931-947. https://doi.org/10.1111/ hic3.12096

Fecha de recepción: 1/VI/2016 Fecha de aceptación: 28/VI/2016 